\title{
Waterpipe smoking in Saudi Arabia: Action plan
}

\author{
Naif Alanazi ${ }^{1}$
}

\section{Dear Editor,}

Waterpipe use has grown exponentially during the last 20 years in Middle-East and Western countries, including the United States. In Saudi Arabia there has been an increasing trend in waterpipe smoking among teenagers and young adults ${ }^{1,2}$. In addition to the spread of waterpipe lounges and cafés, some individuals use private places, such as Estrahas, where they can gather for talking and smoking. Finding an Estraha without a waterpipe smoker is uncommon. Some Estrahas are explicitly used to gather with friends to play cards, play video games, and smoke waterpipe.

Epidemiological data of waterpipe smoking in Saudi Arabia have shown alarming evidence of high waterpipe usage among teenagers and college students, even though studies have overall shown a considerable variation in the prevalence of waterpipe use. For instance, a study of male medical college students in the eastern region of the country measured that the prevalence of waterpipe smoking was $12.6 \%{ }^{3}$. Another study conducted in Al-Hassa, also in eastern Saudi Arabia, showed that current tobacco use was $30.3 \%$ among high school students, and among those current tobacco smokers, $53.9 \%$ were also waterpipe users ${ }^{4}$. Conducted in some colleges of Qassim University, another study revealed that the total prevalence of waterpipe use was $40 \%{ }^{5}$. Moreover, a recent national survey indicated that the overall prevalence of current tobacco smoking was $12.2 \%$ among those 15 years or older with $4.3 \%$ of the total population daily waterpipe users and $1.4 \%$ current daily smokers of cigarettes/cigar and waterpipe users ${ }^{6}$.

Regardless of the variation of waterpipe smoking prevalence, the available statistics are presenting waterpipe use as a severe public health issue in Saudi Arabia. To counterbalance waterpipe smoking in Saudi Arabia, we should consider the following action plan:

First, we need to identify the magnitude of these smoking phenomena. Better social and epidemiological assessments of waterpipe smoking are needed to objectively define the problem and its scope in terms of popularity and its negative consequences on health and society.

Second, we need to create educational interventions. We should identify factors that have the potential to influence waterpipe smoking behaviour. The factors may include health knowledge, personal attitude and perceptions, misconceptions, and beliefs toward waterpipe smoking. We should identify the factors that either encourage or discourage waterpipe use and develop appropriate prevention/ intervention programs targeting waterpipe smoking behaviour.

Third, we need policy assessments, implementation, and improved regulatory actions that require health policymakers to review, edit and update current smoking policies in Saudi Arabia, and ensure regulations are enforced. Such policies should include age restriction regulations for entering waterpipe lounges/cafés, the prohibition of smoking in public places or selling tobacco to minors, appropriate monitoring of the constituents of waterpipe tobacco, the
AFFILIATION

1 Department of Public health, College of Health Sciences, Saudi Electronic University, Riyadh, Saudi Arabia

CORRESPONDENCE TO Naif Alanazi. Department of Public health, College of Health Sciences, Saudi Electronic University, Abu Bakr Street, Riyadh 11673, Saudi Arabia.

E-mail: n.alanazi@seu.edu.sa

\section{KEYWORDS}

smoking, tobacco smoking, waterpipe smoking, hookah

Received: 6 November 2018 Revised: 20 April 2019

Accepted: 20 April 2019 
standardization of waterpipe tobacco production, the addition of visible warning labels in each waterpipe tobacco box, and the removal of deceptive labels or descriptions, such as ' $0 \%$ tar', ' $0 \%$ nicotine', or ' $100 \%$ natural', etc.

To conclude, health officials and public health professionals should declare waterpipe use a severe threat to public health. More funds and research are required to build evidence-based comprehensive tobacco waterpipe prevention/intervention strategies. Available facts and evidence can be used to begin policy and regulatory actions. Delaying or taking no action will lead to continued ineffective control over waterpipe use that may result in adverse public health outcomes.

\section{REFERENCES}

1. Akl EA, Gunukula SK, Aleem S, et al. The prevalence of waterpipe tobacco smoking among the general and specific populations: a systematic review. BMC Public Health. 2011;11(1):244. doi:10.1186/1471-2458-11-244

2. Al Mohamed H, Amin T. Pattern and prevalence of smoking among students at King Faisal University, Al Hassa, Saudi Arabia. 2010;16(1):56-64. doi:10.26719/2010.16.1.56

3. Taha AZ, Sabra AA, Al-Mustafa ZZ, Al-Awami HR, Al-Khalaf MA, Al-Momen MM. Water pipe (shisha) smoking among male students of medical colleges in the eastern region of Saudi Arabia. Annals of Saudi Medicine. 2010;30(3):222. doi:10.4103/0256-4947.62838

4. Amin TT, Amr M, Zaza BO, Suleman W. Harm perception, attitudes and predictors of waterpipe (shisha) smoking among secondary school adolescents in Al-Hassa, Saudi Arabia. Asian Pac J Cancer Prev. 2010;11(2):293-301.

5. Alzohairy MA. Water pipe \& cigarette smoking among Qassim University male students: prevalence and beliefs. International Journal of Health Sciences. 2012;6(1):45. doi:10.12816/0005972

6. Moradi-Lakeh M, El Bcheraoui C, Tuffaha M, et al. Tobacco consumption in the Kingdom of Saudi Arabia, 2013: findings from a national survey. BMC Public Health. 2015;15(1):611. doi:10.1186/s12889-015-1902-3 